\title{
Putting genome-wide sequencing in neonates into perspective
}

\author{
Pleuntje J. van der Sluijs, MSc${ }^{1}$, Emmelien Aten, MD, $\mathrm{PhD}^{1}$, \\ Daniela Q. C. M. Barge-Schaapveld, MD, PhD ${ }^{1}$, Emilia K. Bijlsma, MD, PhD ${ }^{1}$, \\ Regina Bökenkamp-Gramann, MD, PhD², Laura Donker Kaat, MD, PhD ${ }^{1,3}$,
}

Remco van Doorn, $\mathrm{MD}, \mathrm{PhD}^{4}$, Dietje Fransen van de Putte, $\mathrm{MD}, \mathrm{PhD}^{1}$, Arie van Haeringen, $\mathrm{MD}^{1}$, Arend D. J. ten Harkel, MD, PhD ${ }^{2}$, Yvonne Hilhorst-Hofstee, MD, PhD ${ }^{1}$, Mariette J. V. Hoffer, PhD ${ }^{1}$, Nicolette S. den Hollander, MD, PhD ${ }^{1}$, Yvette van lerland, MD, PhD ${ }^{1}$, Marije Koopmans, MD, PhD ${ }^{1}$, Marjolein Kriek, MD, PhD ${ }^{1}$, Setareh Moghadasi, MD ${ }^{1}$, Esther A. R. Nibbeling, PhD ${ }^{1}$, Cacha M. P. C. D. Peeters-Scholte, MD, PhD ${ }^{5}$, Thomas P. Potjer, MD ${ }^{1}$, Maartje van Rij, MD, PhD ${ }^{1}$, Claudia A. L. Ruivenkamp, PhD ${ }^{1}$, Julie W. Rutten, MD, PhD ${ }^{1}$, Sylke J. Steggerda, MD, PhD $^{6}$, Manon Suerink, MD ${ }^{1}$, Ratna N. G. B. Tan, MD ${ }^{6}$, Karin van der Tuin, MD ${ }^{1}$, Remco Visser, MD, PhD $^{6}$, Anne-Sophie van der Werf -'t Lam, MD ${ }^{1}$, Monique Williams, MD, PhD ${ }^{7}$, Ruben Witlox, MD ${ }^{6}$ and Gijs W. E. Santen, MD, PhD ${ }^{1}$

Purpose: Several studies have reported diagnostic yields up to $57 \%$ for rapid exome or genome sequencing (rES/GS) as a single test in neonatal intensive care unit (NICU) patients, but the additional yield of rES/GS compared with other available diagnostic options still remains unquantified in this population.

Methods: We retrospectively evaluated all genetic NICU consultations in a 2-year period.

Results: In 132 retrospectively evaluated NICU consultations 27 of 32 diagnoses $(84.4 \%)$ were made using standard genetic workup. Most diagnoses (65.6\%) were made within 16 days. Diagnostic ES yield was 5/29 (17.2\%). Genetic diagnoses had a direct effect on clinical management in $90.6 \%(29 / 32)$ of patients.

Conclusions: Our study shows that exome sequencing has a place in NICU diagnostics, but given the associated costs and the high yield of alternative diagnostic strategies, we recommend to first perform clinical genetic consultation.

Genetics in Medicine (2019) 21:1074-1082; https://doi.org/10.1038/s41436018-0293-0

Keywords: ES; NICU; clinical geneticists; rapid; sequencing

\section{INTRODUCTION}

Exome sequencing (ES) and genome sequencing (GS) are increasingly being applied in the neonatal setting. It has been suggested that rapid sequencing is particularly relevant in this population, because major clinical decisions could be affected by a genetic diagnosis. ${ }^{1,2}$ The first report of rapid genomewide sequencing $(\mathrm{rES} / \mathrm{GS})$ in neonatal intensive care unit (NICU) patients dates from $2015^{2}$ and reported 2-7 day turnaround times, whereas regular diagnostic turnaround times are currently significantly longer (up to several months). This study found a diagnostic yield of 57\%, among the highest in sequencing studies, suggesting that rES/GS should be implemented broadly in NICUs worldwide. However, this paper and other papers reporting $\mathrm{rES} / \mathrm{GS}^{2-4}$ limit their data to cases where rES/GS was primarily applied, and also perform $\mathrm{rES} / \mathrm{GS}$ in patients with a clinical suspicion of a syndrome. This explains why usually recognizable syndromes, such as CHARGE or Noonan syndrome, are among the diagnoses made in rES/GS reports. ${ }^{1-3}$ Therefore, it could be argued that the actual added value of ES/GS in general, and $\mathrm{rES} / \mathrm{GS}$ in particular, compared with a more classical clinical genetic approach, has not been properly

${ }^{1}$ Department of Clinical Genetics, Leiden University Medical Center, Leiden, The Netherlands; ${ }^{2}$ Department of Pediatric Cardiology, Leiden University Medical Center, Leiden, The Netherlands; ${ }^{3}$ Department of Neurology, Erasmus Medical Center, Rotterdam, The Netherlands; ${ }^{4}$ Department of Dermatology, Leiden University Medical Center, Leiden, The Netherlands; ${ }^{5}$ Department of Neurology, Leiden University Medical Center, Leiden, The Netherlands; ${ }^{6}$ Department of Pediatrics, Division of Neonatology, Leiden University Medical Center, Leiden, The Netherlands; ${ }^{7}$ Department of Pediatrics, Leiden University Medical Center, Leiden, The Netherlands. Correspondence: Gijs W. E. Santen (santen@lumc.nl) 
assessed. Although no one will doubt that ES/GS will lead to a higher diagnostic yield, it is relevant to know the extent of improvement given the limited availability of ES/GS in many countries, the high associated costs, and the fact that most health-care systems have limited financial resources.

Although a randomized controlled trial would be the best method to determine the added value of ES/GS, such studies would require large sample sizes due to the incredible heterogeneity in NICU presentations, and face additional difficulties due to rapid changes in availability of genetic testing as recently illustrated. ${ }^{1}$ We therefore decided to perform a retrospective observational study of all clinical genetic NICU consultations in a 2-year period.

\section{Selection of patients}

\section{MATERIALS AND METHODS}

All patients who received clinical genetic consultation at the neonatal medium or intensive care (NICU) or pediatric intensive care (PICU) in the Leiden University Medical Center (LUMC) between September 2014 and September 2016 and were aged $\leq 120$ days were included.

A waiver of consent was granted by the Institutional Review Board (IRB) of the LUMC.

\section{Genetic investigations}

Before or simultaneously with ES a Cytoscan High DensityArray (ThermoFisher) was performed to detect copynumber variation. ES could consist of either trio ES (including parents) or single patient ES, and consisted of Agilent SureSelect v5 capture followed by Sequencing on Illumina platforms (Hiseq2500 or Hiseq4000). Analysis was performed in the LUMC's clinical genetic laboratory using a GATKbased pipeline ${ }^{5}$ and in-house developed analysis software (LOVD+).

ES was performed after clinical genetic consultation, consent from the parents, and if one of the following conditions was met:

- Isolated cardiac anomaly (mostly single ES)

- Combination of multiple congenital anomalies, or a congenital anomaly with dysmorphic features, in the absence of a clinical diagnosis

- Delayed development or, e.g., persisting feeding problems at follow-up (FU)

\section{Data collection}

Clinical notes were retrospectively evaluated to determine the referral reason for genetic consultation and document the presenting features including congenital malformations in each patient.

Regarding the outcome of each patient, the following categories were defined:

- Genetic diagnosis: all patients in whom the genetic diagnosis is considered to explain the most important features of their phenotype
- Likely syndromic: patients with multiple malformations, or significant developmental delay on FU, but without genetic diagnosis

- Nongenetic: patients with alternative, nongenetic causes that likely explained their complete phenotype

- Isolated/spontaneously resolving: patients with normal development on FU, in whom either the phenotype had disappeared (e.g., hypotonia), or the congenital malformation appeared to be an isolated, most likely multifactorial determined feature

- Lost to FU: patients for whom the appropriate category could not be determined with the available clinical data

To evaluate the effect of a genetic diagnosis on medical management, we used the categories proposed by Meng et $\mathrm{al}^{3}$ These categories are redirection of care, initiation of new subspecialist care, changes in medication or diet, and major procedures. To specify the second category further, we made four subcategories: positive screening (i.e., additional screening led to detection of additional anomalies), negative screening (i.e., additional screening led to the exclusion of associated features), future screening, and tumor screening.

We determined the time to diagnosis as the time between the consultation and the clinical or molecular diagnosis, whichever came first. A diagnosis was considered fast when it was made within 16 days after consultation. A clinical diagnosis was recorded when the diagnosis was communicated to the parents as the most likely diagnosis and informed clinical management.

\section{Statistics}

All performed statistical tests were two-sided. The applied tests are indicated in the respective tables. No multiplicity correction was performed.

\section{Patient characteristics}

\section{RESULTS}

One hundred thirty-two infants received a genetic consultation and were retrospectively included within the 2-year observation period (Fig. 1, Table 1). Most of these patients $(94.7 \%, 125 / 132)$ were seen at the NICU or PICU, while the others were seen in neonatal medium care settings $(n=7)$. At some time during their admission three of these seven patients were admitted to the NICU. The most frequent referral reasons were congenital cardiac anomalies $(39 \%, 51 / 132)$, dysmorphic features $(11 \%, 14 / 132)$, and brain anomalies $(8 \%, 11 / 132)$. Clinical genetic consultation took place at a median age of 3 days after birth (range 0-115 days). In four patients molecular diagnostics had been performed prenatally, leading to a presumptive diagnosis. The duration of IC admission varied from 0 to 129 days with a median of 10 days. Of the included patients 20 died (age of death 0-655 days, median 14 days); ES was performed in 7 of these 20 patients. 


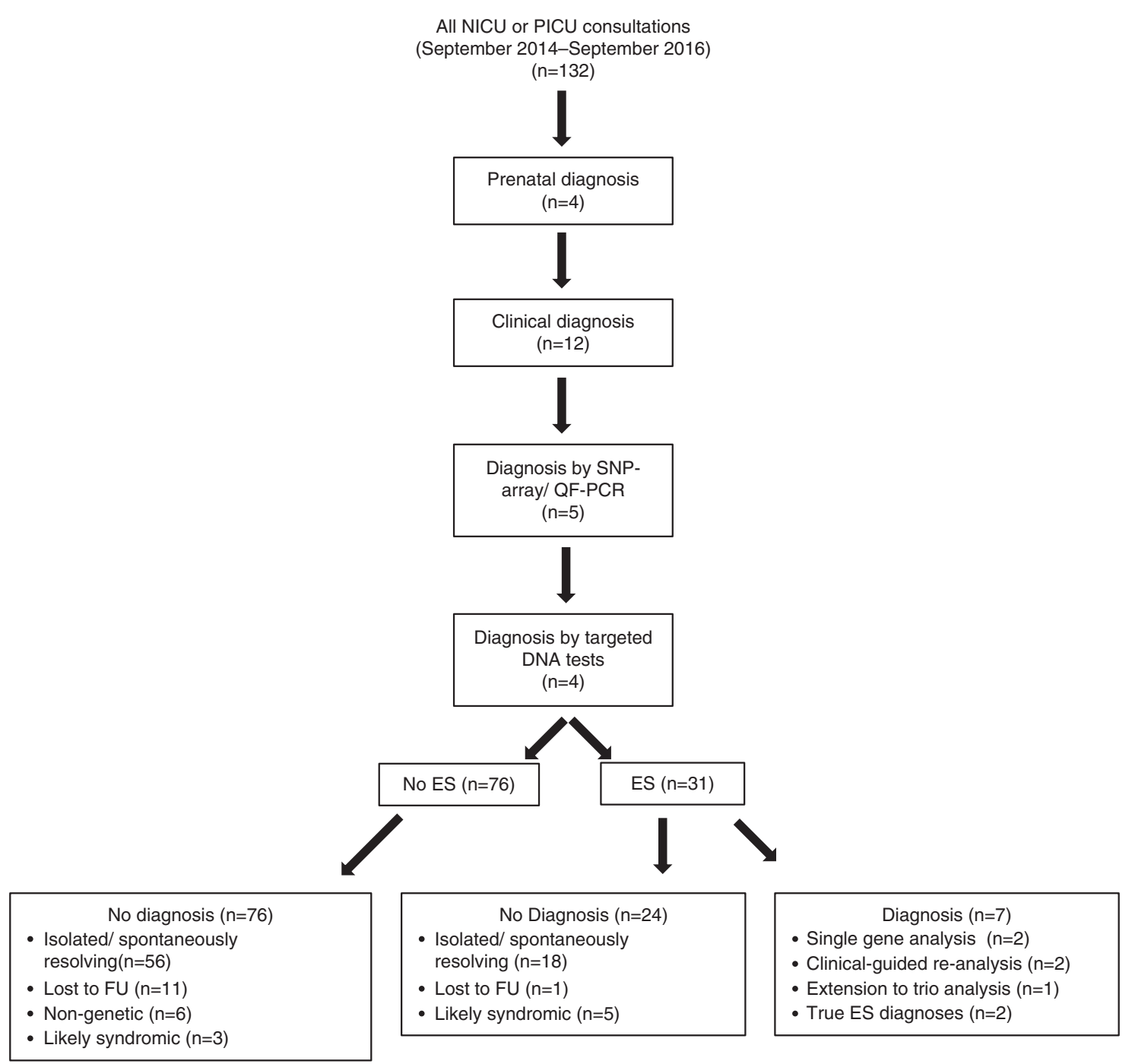

Fig. 1 Schematic overview of study results. ES exome sequencing, FU follow-up, NICU neonatal intensive care unit, PICU pediatric intensive care unit, QF-PCR quantitative fluorescence polymerase chain reaction, SNP single-nucleotide polymorphism.

\section{Diagnostics}

In $32 / 132$ patients $(24.2 \%)$ a genetic diagnosis was obtained (Table 2 and Table S1). Excluding Down syndrome and prenatal diagnoses the diagnostic yield was $18.0 \%(22 / 122)$. A substantial number of these diagnoses were clinical diagnoses based on the pattern of congenital malformations and dysmorphic features $(37.5 \%, 12 / 32$, excluding Down syndrome $26.9 \%, 7 / 26)$. All clinical diagnoses were made on the day of consultation, except for the diagnosis of Kabuki syndrome, which was made 11 days later, and all were eventually confirmed by molecular genetic testing (0-69 days, median 11; excluding Down syndrome 5-69 days, median 25). In addition, one suspicion of Down syndrome was confirmed using QF-PCR and eight diagnoses were made using array analyses, including four prenatal diagnoses. Array results were usually obtained within 2 weeks after the genetic consultation (excluding prenatal diagnoses: range 10-17 days, median 14 days), resulting in a total of fast diagnoses of $60.7 \%$ (17/28) (excluding prenatal diagnoses: median 0 days, range
0-16 days). Eleven late diagnoses were made 34-991 days (median 164 days) after the first genetic consultation. In four of these cases, a targeted molecular test (such as a Noonan gene panel) with relatively long turnaround time was requested because of a clinical suspicion (55-311 days, median 115 days).

Most of the 100 patients without a genetic diagnosis were classified as isolated/spontaneously resolving ( $n=74,74.0 \%)$, while 12 were lost to follow-up, 6 were classified as nongenetic, and 8 were categorized as likely syndromic. In 5 of these 8 likely syndromic patients, ES was performed but did not yield a diagnosis.

\section{Exome sequencing}

ES was performed in $31 / 132$ patients (24 trio ES, 7 single ES). The time to request ES after consultation ranged from 0 to 499 days with a median of 124 days. In two cases a positive ES result was obtained after a single gene was analyzed from the ES data because of a prior clinical suspicion (CHRNG, CHD7). 
Table 1 Patient characteristics

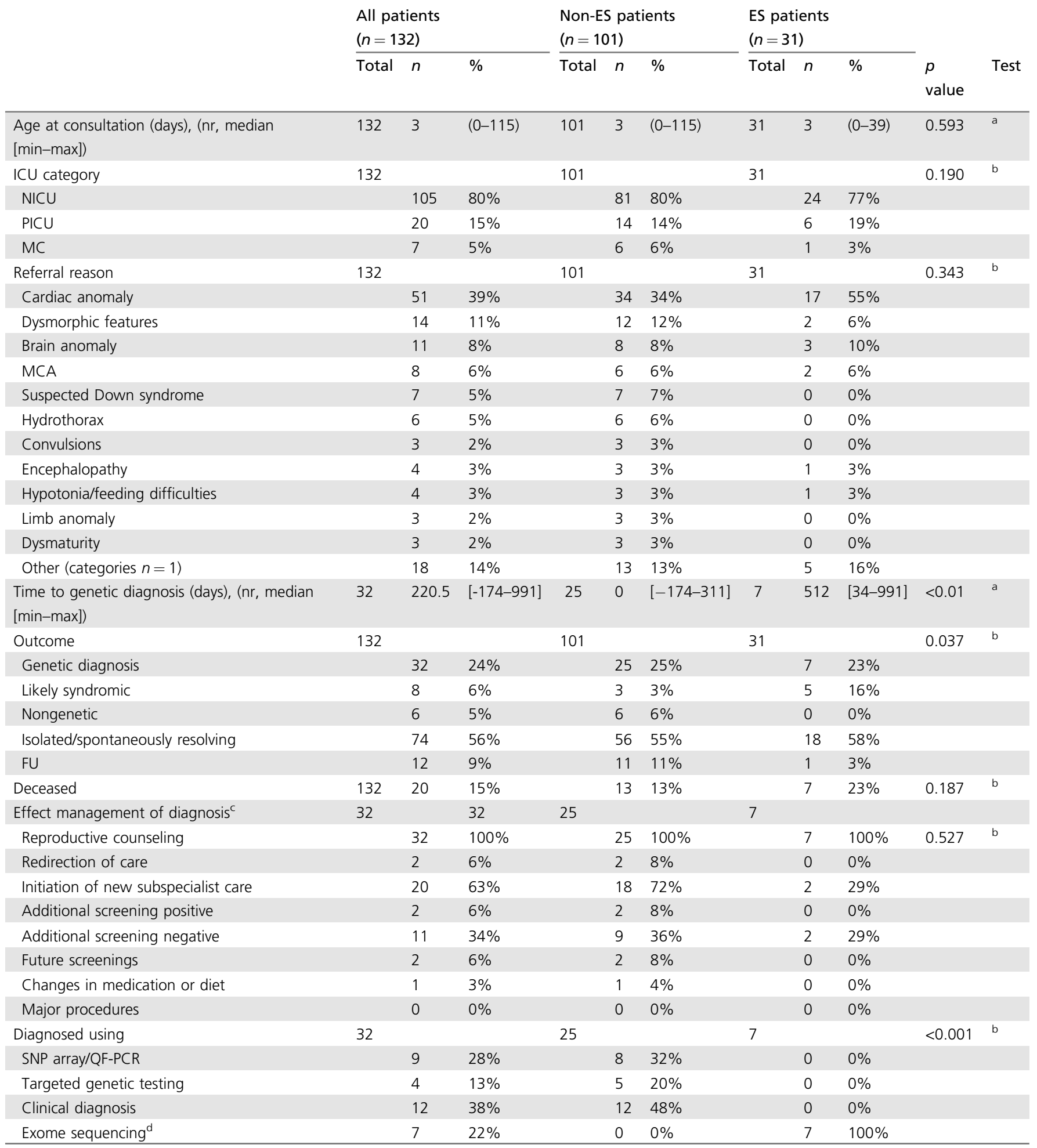

ES exome sequencing, FU follow-up, ICU intensive care, MC medium care, MCA multiple congenital anomalies, NICU neonatal intensive care, $n r$ number, PICU pediatric intensive care, $Q F-P C R$ quantitative fluorescence polymerase chain reaction, SNP single-nucleotide polymorphism.

a Mann-Whitney $U$.

${ }^{\mathrm{b}}$ Chi-square.

'Per patient more than one consequence was possible.

${ }^{\mathrm{d}}$ Two ES diagnoses were made after a single gene was analyzed. Consequently, total ES yield 17.2\% (5/29). 
Table 2 Characteristics of patients with a genetic diagnosis

\begin{tabular}{|c|c|c|c|c|c|c|c|c|c|c|c|c|}
\hline $\begin{array}{l}\text { Patient } \\
\text { ID }\end{array}$ & $\begin{array}{l}\text { Age } \\
\text { consultation } \\
\text { (days) }\end{array}$ & $\begin{array}{l}\text { Age } \\
\text { death } \\
\text { (days) }\end{array}$ & Gene & Inheritance & Disease name & $\begin{array}{l}\text { OMIM } \\
\text { (disease) }\end{array}$ & $\begin{array}{l}\text { OMIM } \\
\text { (gene[s]) }\end{array}$ & $\begin{array}{l}\text { Diagnosed } \\
\text { using: }\end{array}$ & $\begin{array}{l}\text { Time to } \\
\text { diagnosis } \\
\text { (days) }\end{array}$ & $\begin{array}{l}\text { Consequences of } \\
\text { diagnosis }^{\mathrm{a}}\end{array}$ & $\begin{array}{l}\text { Future } \\
\text { screening }\end{array}$ & $\begin{array}{l}\text { Diagnosis } \\
\text { before } \\
\text { discharge }\end{array}$ \\
\hline 1 & 3 & 6 & ATAD3A & Recessive & $\begin{array}{l}\text { ATAD3A-related } \\
\text { pontocerebellar } \\
\text { hypoplasia }\end{array}$ & & $\begin{array}{l}\text { *612316; } \\
\text { *612317 }\end{array}$ & $\begin{array}{l}\text { ES/ } \\
\text { reanalysis }\end{array}$ & 991 & None (died) ${ }^{a}$ & & No \\
\hline 2 & 1 & & PTPN11 & Dominant & Noonan syndrome & 163950 & *176876 & $\begin{array}{l}\text { Targeted } \\
\text { diagnostics }\end{array}$ & 55 & $\begin{array}{l}\text { Additional } \\
\text { screening } \\
\text { (negative) }\end{array}$ & $x$ & No \\
\hline 3 & 2 & & NPC1 & Recessive & Niemann-Pick type C & 257220 & *607623 & $\begin{array}{l}\text { Targeted } \\
\text { diagnostics }\end{array}$ & 68 & & & No \\
\hline 3 & 2 & & OTOA & Recessive & $\begin{array}{l}\text { Autosomal recessive } \\
\text { deafness type } 22\end{array}$ & 607039 & *607038 & $\begin{array}{l}\text { ES-based } \\
\text { hearing loss } \\
\text { panel }\end{array}$ & 167 & & & No \\
\hline 4 & 2 & & $T 21$ & Chromosomal & Down syndrome & 190685 & 190685 & $\begin{array}{l}\text { Clinical } \\
\text { diagnosis }\end{array}$ & 0 & $\begin{array}{l}\text { Initiation of new } \\
\text { subspecialist care }\end{array}$ & $x$ & Yes \\
\hline 5 & 1 & & $T 21$ & Chromosomal & Down syndrome & 190685 & 190685 & $\begin{array}{l}\text { Clinical } \\
\text { diagnosis }\end{array}$ & 0 & $\begin{array}{l}\text { Initiation of new } \\
\text { subspecialist care }\end{array}$ & $x$ & Yes \\
\hline 6 & 2 & & PTPN11 & Dominant & Noonan syndrome & 163950 & *176876 & $\begin{array}{l}\text { Clinical } \\
\text { diagnosis }\end{array}$ & 0 & & $x$ & Yes \\
\hline 7 & 3 & & CDK13 & Dominant & CDK13 syndrome & 617360 & *603309 & $\begin{array}{l}\text { ES/ } \\
\text { reanalysis }\end{array}$ & 938 & & & No \\
\hline 8 & 2 & & Chromosomal & Dominant & $\begin{array}{l}22 \mathrm{q} 11 \text { deletion } \\
\text { syndrome }\end{array}$ & 187500 & 611867 & SNP array & PND & $\begin{array}{l}\text { Additional } \\
\text { screening } \\
\text { (negative); } \\
\text { irradiated blood for } \\
\text { surgery }\end{array}$ & & Yes \\
\hline 9 & 4 & & SLC6A9 & Recessive & $\begin{array}{l}\text { Glycine } \\
\text { encephalopathy }\end{array}$ & 617301 & *601019 & $\begin{array}{l}\text { ES/ } \\
\text { reanalysis }\end{array}$ & 512 & & & No \\
\hline 10 & 0 & & COL2A1 & Dominant & $\begin{array}{l}\text { Spondyloepiphyseal } \\
\text { dysplasia congenita }\end{array}$ & 183900 & *120140 & $\begin{array}{l}\text { Targeted } \\
\text { diagnostics }\end{array}$ & 311 & $\begin{array}{l}\text { Additional } \\
\text { screening } \\
\text { (negative) }\end{array}$ & & No \\
\hline 11 & 3 & & $T 21$ & Chromosomal & Down syndrome & 190685 & 190685 & QF-PCR & 1 & $\begin{array}{l}\text { Initiation of new } \\
\text { subspecialist care }\end{array}$ & $x$ & Yes \\
\hline 12 & 0 & & $T 21$ & Chromosomal & Down syndrome & 190685 & 190685 & $\begin{array}{l}\text { Clinical } \\
\text { diagnosis }\end{array}$ & 0 & $\begin{array}{l}\text { Initiation of new } \\
\text { subspecialist care }\end{array}$ & $x$ & Yes \\
\hline 13 & 0 & & CHD7 & Dominant & CHARGE syndrome & 214800 & *608892 & $\begin{array}{l}\text { ES (targeted } \\
\text { readout) }\end{array}$ & 130 & $\begin{array}{l}\text { Additional } \\
\text { screening } \\
\text { (negative) }\end{array}$ & $x$ & No \\
\hline 14 & 0 & & $T 21$ & Chromosomal & Down syndrome & 190685 & 190685 & $\begin{array}{l}\text { Clinical } \\
\text { diagnosis }\end{array}$ & 0 & $\begin{array}{l}\text { Initiation of new } \\
\text { subspecialist care }\end{array}$ & $x$ & Yes \\
\hline 15 & 3 & & Chromosomal & Dominant & 1q24.3-q31.1del & & & SNP array & 13 & $\begin{array}{l}\text { Additional } \\
\text { screening } \\
\text { (negative) }\end{array}$ & & Yes \\
\hline 16 & 1 & & Chromosomal & Dominant & $1 \mathrm{q} 21.1$ & 612474 & & SNP array & PND & & & Yes \\
\hline 17 & 23 & & NSD1 & Dominant & Sotos syndrome & 117550 & *606681 & $\begin{array}{l}\text { Targeted } \\
\text { diagnostics }\end{array}$ & 162 & $\begin{array}{l}\text { Additional } \\
\text { screening } \\
\text { (negative) }\end{array}$ & $x$ & No \\
\hline 18 & 4 & & PWS & $\begin{array}{l}\text { Dominant } \\
\text { (imprinted) }\end{array}$ & Prader-Willi syndrome & 176270 & & SNP array & 15 & $\begin{array}{l}\text { Early treatment } \\
\text { with GH }\end{array}$ & $x$ & Yes \\
\hline 19 & 1 & 655 & CHD7 & Dominant & CHARGE syndrome & 214800 & *608892 & $\begin{array}{l}\text { Clinical } \\
\text { diagnosis }\end{array}$ & 0 & $\begin{array}{l}\text { Identification of } \\
\text { additional } \\
\text { anomalies }\end{array}$ & $x$ & Yes \\
\hline 20 & 2 & 8 & Chromosomal & Chromosomal & $\begin{array}{l}\text { 17q12q25.3dup } \\
\text { 12p13.33p13.32dup } \\
\text { (high mosaic) }\end{array}$ & & & SNP array & PND & $\begin{array}{l}\text { Initiation of } \\
\text { palliative care }\end{array}$ & & Yes \\
\hline 21 & 1 & & CHRNG & Recessive & Escobar syndrome & 265000 & *100730 & $\begin{array}{l}\text { ES (targeted } \\
\text { readout) }\end{array}$ & 130 & None $^{\mathrm{a}}$ & & No \\
\hline 22 & 27 & & KMT2A & Dominant & $\begin{array}{l}\text { Wiedemann-Steiner } \\
\text { syndrome }\end{array}$ & 605130 & *159555 & ES & 34 & $\begin{array}{l}\text { Additional } \\
\text { screening } \\
\text { (negative) }\end{array}$ & $x$ & No \\
\hline 23 & 0 & & PIK3CA & $\begin{array}{l}\text { Dominant } \\
\text { (mosaic) }\end{array}$ & $\begin{array}{l}\text { PIK3CA-related } \\
\text { disorders }\end{array}$ & 612918 & *171834 & $\begin{array}{l}\text { Clinical } \\
\text { diagnosis }\end{array}$ & 0 & $\begin{array}{l}\text { Additional } \\
\text { screening } \\
\text { (negative); tumor } \\
\text { screening }\end{array}$ & $x$ & Yes \\
\hline 24 & 3 & 6 & GLDC & Recessive & $\begin{array}{l}\text { Glycine biosynthesis } \\
\text { deficiency }\end{array}$ & 605899 & *238300 & $\begin{array}{l}\text { Clinical } \\
\text { diagnosis }\end{array}$ & 0 & $\begin{array}{l}\text { Initiation of } \\
\text { palliative care }\end{array}$ & & Yes \\
\hline 25 & 1 & & Chromosomal & Chromosomal & $\begin{array}{l}\text { 46,XX,der(21)t(11;21) } \\
\text { (p15.4;q22.2) } \\
\text { Beckwith-Wiedemann } \\
\text { syndrome }\end{array}$ & 130650 & & SNP array & 10 & Tumor screening & & Yes \\
\hline 26 & 1 & & CHD7 & Dominant & CHARGE syndrome & 214800 & *608892 & $\begin{array}{l}\text { Clinical } \\
\text { diagnosis }\end{array}$ & 0 & $\begin{array}{l}\text { Identification of } \\
\text { additional } \\
\text { anomalies }\end{array}$ & $x$ & Yes \\
\hline 27 & 1 & & $T 21$ & Chromosomal & Down syndrome & 190685 & 190685 & $\begin{array}{l}\text { Clinical } \\
\text { diagnosis }\end{array}$ & 0 & $\begin{array}{l}\text { Initiation of new } \\
\text { subspecialist care }\end{array}$ & $x$ & Yes \\
\hline 28 & 0 & & NIPBL & Dominant & $\begin{array}{l}\text { Cornelia de Lange } \\
\text { syndrome }\end{array}$ & 122470 & *608667 & $\begin{array}{l}\text { Clinical } \\
\text { diagnosis }\end{array}$ & 0 & $\begin{array}{l}\text { Additional } \\
\text { screening } \\
\text { (negative) }\end{array}$ & $x$ & Yes \\
\hline 29 & 11 & & Chromosomal & Dominant & 18p11.22del & 146390 & & SNP array & 16 & $\begin{array}{l}\text { Additional } \\
\text { screening } \\
\text { (negative) }\end{array}$ & & No \\
\hline 30 & 39 & & $A D N P$ & Dominant & $\begin{array}{l}\text { Helsmoortel-van der } \\
\text { Aa syndrome }\end{array}$ & 615873 & *611386 & ES & 516 & $\begin{array}{l}\text { Additional } \\
\text { screening } \\
\text { (negative) }\end{array}$ & & No \\
\hline 31 & 0 & 22 & KMT2D & Dominant & Kabuki syndrome & 147920 & *602113 & $\begin{array}{l}\text { Clinical } \\
\text { diagnosis }\end{array}$ & 11 & None (died) ${ }^{\mathrm{a}}$ & X (died) & Yes \\
\hline 32 & 2 & & Chromosomal & Chromosomal & $\begin{array}{l}47, X Y,+\operatorname{der}(10) t(5 ; 10) \\
\text { (p15.3;q11.2) }\end{array}$ & & & SNP array & PND & $\begin{array}{l}\text { Additional } \\
\text { screening } \\
\text { (negative) }\end{array}$ & & Yes \\
\hline
\end{tabular}

ES exome sequencing, GH growth hormone, MCA multiple congenital anomalies, PND prenatal diagnostics, QF-PCR quantitative fluorescence polymerase chain reac-

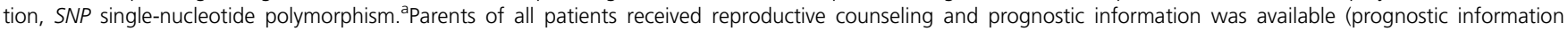
was not given for patients 1 and 31 because they had died at the time of diagnoses, nor for patients 21 and 32 for whom insufficient prognostic information was available). 
In two other cases, a diagnosis was initially missed by ES, but clinically guided reanalysis did provide pathogenic variants in newly described genes (SLC6A9 and $A T A D 3 A^{6}$ ). In a patient with a heart defect, panel ES did not provide the causative variant, but full trio ES identified a pathogenic variant in CDK13. In the remaining $26 \mathrm{ES}, 2$ diagnoses were made (KMT2A, Wiedemann-Steiner syndrome [OMIM 605130] and $A D N P$, Helsmoortel-van der Aa syndrome [OMIM $615873])$. The immediate clinical yield was therefore $2 / 29$ $(6.8 \%)$, while the total yield was $5 / 29$ (17.2\%).

\section{Factors influencing diagnostic yield}

To assess whether the clinical presentation of patients influenced the probability of obtaining a genetic diagnosis, we investigated the effects of (1) referral reason, (2) influence of the presence or absence of clinical features, and (3) number of affected organ systems.

When observing the odds ratios for obtaining a diagnosis per referral reason (Table 3 , left part), it is clear that patients referred because of a suspicion of Down syndrome were most likely to obtain a genetic diagnosis. Patients referred because of encephalopathy and hypotonia/feeding difficulties, as well as patients with limb anomalies also showed high odds ratios, whereas patients referred primarily because of cardiac or brain anomalies showed a relatively low odds ratio. Many of these odds ratios do not differ significantly from 1, which is likely due to the low sample size per referral category. For ES the sample size is even smaller, but it is interesting to note that the diagnostic yield in patients referred primarily because of cardiac anomalies tended to be lower.

Irrespective of the referral reason, we also analyzed whether the presence of anomalies in organ systems influenced the chance of a clinical diagnosis (Table 3 ). This table shows that all odds ratios are close to and include 1. Only the presence of evident dysmorphic features seems to increase the chance of a diagnosis $(p=0.074)$.

We also evaluated whether the number of affected organ systems influenced the diagnostic yield. No effect was found of the number of reported anomalies on the diagnostic yield (Table 3, bottom).

\section{Consequences of genetic diagnoses}

All diagnosed patients received genetic counseling, providing their parents with relevant information for possible future pregnancies. In $90.6 \%$ (29/32) of diagnosed patients we were able to inform the parents about the prognosis associated with the genetic diagnosis (Table 2 and Table S1). In the other three patients, either insufficient information was present because limited clinical data were published $(C H R N G)$ or the patient had already died (Kabuki syndrome, ATAD3A). Disregarding tumor screening, for 16 patients the diagnoses had long-term management consequences such as future screening for disease-associated features. Furthermore, in most patients the diagnosis led to initiation of new subspecialist care $(62.5 \%, 20 / 32)$, often additional screening. Screening led to additional findings in two patients $(2 \mathrm{x}$
CHARGE syndrome [OMIM 214800]). Of the 12 patients where the additional screening showed no abnormalities, 6 had an indication for future screening. In addition, two patients received redirection of care (i.e., initialization of palliative care $[n=2])$. In two patients the genetic diagnosis led to initiation of a tumor screening program (Beckwith-Wiedemann syndrome [OMIM 130650] and CLOVES syndrome [OMIM 612918]). A change in medication was received by a patient with Prader-Willi syndrome (OMIM 176270); an early treatment with growth hormone was started although there is currently no evidence that such an early start of growth hormone treatment provides additional benefits over a start at 6 months per protocol.

\section{DISCUSSION}

Rapid genome-wide sequencing has been advocated as a high yield diagnostic test in NICU patients, but the studies published thus far have not directly assessed the additional yield compared with more classical genetic approaches. In this study, we have retrospectively included all 132 genetic NICU/ PICU consultations over a 2-year period. The overall diagnostic yield of ES was 5/29 (17.2\%).

\section{Comparison with other NICU studies \\ Setting}

The LUMC functions as an expertise center for neonatal cardiac surgery, whereas other types of neonatal surgery are referred to other hospitals and are lacking from our patient population. Even though we were less strict in the inclusion of patients (medium care patients were also included), and despite our biased patient population, the list of diagnoses seems comparable with diagnoses typically made in other papers. $^{2-4,7}$ The presence of multiple patients with Noonan, CHARGE, and Kabuki syndrome and severe early-onset metabolic disorders clearly shows overlap.

\section{Diagnostic yield}

Based on our data, the additional yield of ES over other diagnostic tools is $17.2 \%$. We have recalculated the yields of other NICU papers, taking into account unrecognizable or atypical presentations only, and these are relatively similar to our findings (Table 4).

We did not identify particular clinical features that were predictive of the chance of a genetic diagnosis, although the number of included patients per category is small. Meng et al. $^{3}$ reported a lower diagnostic rate for patients with cardiac anomalies and a higher rate for patients with "abnormalities of the musculature," and our relatively low odds ratio for a genetic diagnosis in patients referred because of cardiac anomalies seems to corroborate this finding. No association was found between the number of reported features and a genetic diagnosis. This is contrary to the findings of Trujillano et al., who showed that a higher number of Human Phenotype Ontology (HPO) terms is associated with a higher diagnostic yield. Important differences between these studies are the number of included 


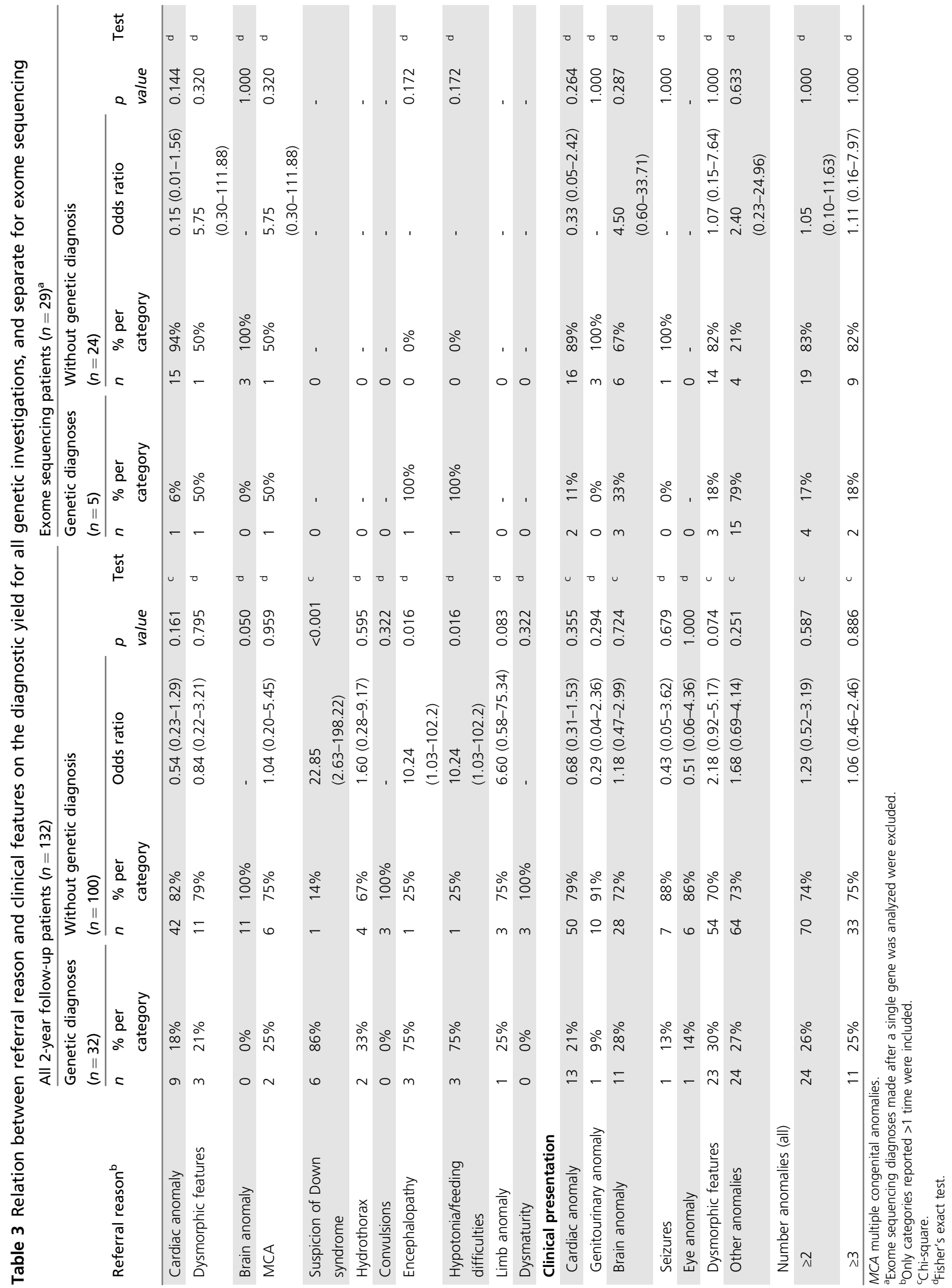


Table 4 Overview of the calculation of the yield of unsuspected diagnoses in sequencing studies performed in NICU infants

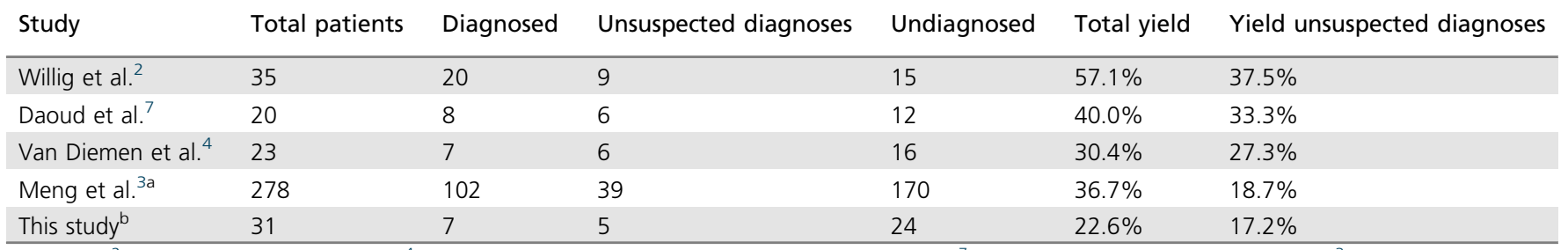

Willig et al. ${ }^{2}$ (2015) and Van Diemen et al. ${ }^{4}$ (2017) performed rapid genome sequencing; Daoud et al. ${ }^{7}$ (2016) used a gene panel; Meng et al. ${ }^{3}$ (2017) performed regular and rapid exome sequencing; this study performed only regular exome sequencing.

NICU neonatal intensive care unit.

${ }^{a}$ An additional six patients were diagnosed retrospectively with myotonic dystrophy, infantile botulism, and four partial diagnoses.

${ }^{b}$ Exome sequencing patients only.

patients and the fact that our cohort is limited to NICU or PICU infants. It is possible that the admission to NICU/PICU in itself significantly raises the possibility of a genetic diagnosis and that therefore the effect of the number of reported features cannot be ascertained with our sample size.

\section{Consequences of genetic diagnosis}

In almost all patients, the genetic diagnosis had consequences (90.6\%, 29/32), and this remains high when excluding patients only receiving parental reproductive counseling, prognostic information, or future screenings $(68.8 \%, 22 / 32)$. The clinical effect of all genetic diagnoses (68.8\%) is comparable with other NICU studies (Willig et al. ${ }^{2} 13 / 20,65.0 \%$; Daoud et al. ${ }^{7}$ 2/8, 25.0\%; Meng et al. ${ }^{3}$ 53/102, 52.0\%; Van Diemen et al. ${ }^{4} 5 /$ 7, 71.4\%).

One aspect that is difficult to quantify is the reduction in burden and costs of additional investigations because of a genetic diagnosis. For example, in patient 22, who presented with severe feeding difficulties, regular care would have included extensive swallowing tests. In other patients, metabolic testing and biopsies might have been performed in absence of a genetic diagnosis. Unfortunately, the retrospective study design does not lend itself to accurately quantify these aspects.

\section{Exome sequencing or genome sequencing}

Most other NICU studies have used rGS rather than rES. Although ES capture protocols are being refined and optimized, the capture step still takes additional time compared with GS, as evidenced from the faster turnaround times (2-7 days versus 7-14 days) in GS studies. There are other advantages of GS, of which the ability to detect small copy-number changes is clinically the most relevant. On the other hand, ES has a higher coverage and is therefore more suitable to detect postzygotic mosaicism. ${ }^{9}$ Intronic and intergenic coverage do not seem to raise diagnostic yield currently, because previous studies have shown that GS application almost uniquely leads to exonic diagnoses. ${ }^{10-13}$ Despite recent reductions in sequencing costs, ES is still more cost-effective and more widely available than $\mathrm{GS}^{14}{ }^{14}$ and considering our limited financial resources we have chosen to implement a rES protocol in September 2016. When speed is truly of the essence, rGS is preferable.

\section{Conclusion: what is the place of (r)ES/GS in the NICU?}

The data reported in this paper provide a first estimate of the (additional) yield of ES in the NICU. The total yield of ES in our study population is $17 \%$, and although this seems much lower than the previously reported NICU yields, it is actually comparable with the "unsuspected yields" of previous papers (Table 4). Our study shows that the yield of the classical genetic approach is high, and ES should not be performed without prior genetic consultation. This will not only reduce costs, but also increase ES yield as evidenced from several patients in our study where ES was initially negative. Additionally, some diagnoses could not have been obtained from ES in blood, such as the low mosaic variant in PIK3CA in patient 23 , which was only detected in fibroblasts.

It could be argued that a fast diagnosis may be helpful to parents and prevent an extensive diagnostic odyssey. Although this is certainly a valid reason, in a budgetrestrictive health-care system spending money on rapid sequencing protocols (which can be up to twice as expensive as regular sequencing due to lower volumes) means that other procedures cannot be performed. We expect that regular turnaround times of ES will decrease significantly in the coming years, reducing the need for bespoke rapid protocols, while also providing parents with a result in a timely manner.

In conclusion, our retrospective study shows that although ES has a place in NICU diagnostics, its yield may not be as spectacular as indicated by early studies, mostly because many diagnoses may also be obtained by alternative, and much cheaper, strategies in a similar timeframe.

\section{ELECTRONIC SUPPLEMENTARY MATERIAL}

The online version of this article (https://doi.org/10.1038/s41436018-0293-0) contains supplementary material, which is available to authorized users.

\section{DISCLOSURE}

The authors declare no conflicts of interest.

\section{REFERENCES}

1. Petrikin JE, Cakici JA, Clark MM, et al. The NSIGHT1-randomized controlled trial: rapid whole-genome sequencing for accelerated etiologic diagnosis in critically ill infants. NPJ Genom Med. 2018;3:6. 
2. Willig LK, Petrikin JE, Smith LD, et al. Whole-genome sequencing for identification of Mendelian disorders in critically ill infants: a retrospective analysis of diagnostic and clinical findings. Lancet Respir Med. 2015;3:377-387.

3. Meng L, Pammi M, Saronwala A, et al. Use of exome sequencing for infants in intensive care units: ascertainment of severe single-gene disorders and effect on medical management. JAMA Pediatr. 2017;171: e173438.

4. van Diemen CC, Kerstjens-Frederikse WS, Bergman KA, et al. Rapid targeted genomics in critically ill newborns. Pediatrics. 2017;140: e20162854.

5. McKenna A, Hanna M, Banks E, et al. The Genome Analysis Toolkit: a MapReduce framework for analyzing next-generation DNA sequencing data. Genome Res. 2010;20:1297-1303.

6. Peeters-Scholte C, Adama van Scheltema PN, Klumper F, et al. Genotypephenotype correlation in ATAD3A deletions: not just of scientific relevance. Brain. 2017;140:e66.

7. Daoud H, Luco SM, Li R, et al. Next-generation sequencing for diagnosis of rare diseases in the neonatal intensive care unit. CMAJ. 2016;188: E254-260.
8. Trujillano D, Bertoli-Avella AM, Kumar Kandaswamy K, et al. Clinical exome sequencing: results from 2819 samples reflecting 1000 families. Eur J Hum Genet. 2017:25:176-182.

9. Meienberg J, Bruggmann R, Oexle K, Matyas G. Clinical sequencing: is WGS the better WES? Hum Genet. 2016;135:359-362.

10. Sun $Y$, Ruivenkamp CA, Hoffer MJ, et al. Next-generation diagnostics: gene panel, exome, or whole genome? Hum Mutat. 2015;36: 648-655.

11. Lelieveld SH, Spielmann M, Mundlos S, Veltman JA, Gilissen C. Comparison of exome and genome sequencing technologies for the complete capture of protein-coding regions. Hum Mutat. 2015;36: 815-822.

12. LaDuca $H$, Farwell $K D$, Vuong $H$, et al. Exome sequencing covers $>98 \%$ of mutations identified on targeted next generation sequencing panels. PLoS One. 2017;12:e0170843.

13. Gilissen C, Hehir-Kwa JY, Thung DT, et al. Genome sequencing identifies major causes of severe intellectual disability. Nature. 2014;511:344-347.

14. Borghesi A, Mencarelli MA, Memo L, et al. Intersociety policy statement on the use of whole-exome sequencing in the critically ill newborn infant. Ital J Pediatr. 2017;43:100. 